\title{
Optical and structural properties of nanostructured copper oxide thin films as solar selective coating prepared by spray pyrolysis method
}

\author{
M. ASADI, S.M. RoZATI* \\ Department of Physics, University of Guilan, Rasht 41335, Iran
}

\begin{abstract}
Copper (II) oxide thin films were prepared by spray pyrolysis method on soda-lime glass substrates using copper acetate precursor solution. Influence of substrate temperature on structural and optical properties was investigated. Structural analysis of these layers were carried out by X-ray diffraction (XRD). Single phase nature and high crystallinity of CuO nanostructures were observed on XRD patterns. The general appearance of the films was uniform and black in color. FT-IR transmittance spectra confirmed the results from the XRD study. Selective solar absorber coatings of copper oxide $(\mathrm{CuO})$ on stainless steel substrates was prepared by spray pyrolysis method. Effect of deposition temperature on optical properties of thin films was investigated. Optical parameters, absorbance $(\alpha)$ and emittance $(\epsilon)$ were evaluated from reflectance data. It can be deduced that the porous structure, such as a light traps, can greatly enhance absorbance, while the composition, thickness and roughness of thin films can greatly influence the emissivity. Single phase nature and high crystallinity of $\mathrm{CuO}$ nanostructures were observed by XRD patterns. Solar absorbance of thin films were in the range of $85 \%$ to $92 \%$.
\end{abstract}

Keywords: spray pyrolysis; solar selective absorber; optical parameters

\section{Introduction}

Copper oxides are semiconductors and have been studied for several reasons. Cupric oxide $(\mathrm{CuO})$ is a p-type semiconductor, having a band between of 1.21 and $1.51 \mathrm{eV}$ and monoclinic crystal structure. Cuprous oxide $\left(\mathrm{Cu}_{2} \mathrm{O}\right)$ is also a p-type semiconductor having a band gap of approximately $2.0 \mathrm{eV}$ and a cubic crystal structure [1]. Cupric oxide is one of the most important semiconductors with many applications, such as diodes, cathodes in lithium batteries, catalysis, lithium-copper oxide electrochemical cells, field emission devices, gas sensors and so on. It is also a promising semiconductor for solar cell fabrication due to its suitable optical properties. Furthermore, it is attractive as a selective solar absorber since it has a high solar absorbency and a low thermal emittance. It also possesses unusual antiferromagnetic properties. Recently, it has been discovered that $\mathrm{CuO}$ also shows high-temperature

*E-mail: smrozati@guilan.ac.ir superconductivity. $\mathrm{CuO}$ has a monoclinic structure with the lattice parameters $\mathrm{a}=4.684 \AA$, $\mathrm{b}=3.425 \AA, \mathrm{c}=5.129 \AA$, and $\beta=99.28 \AA$. $\mathrm{CuO}$ is a p-type semiconductor which has a band gap reported between 1.2 and $1.9 \mathrm{eV}$ with a black color and partial transparency in the visible range. An important advantage of using $\mathrm{CuO}$ in device applications is that it is non-toxic and availability of its constituents is almost limitless. Various synthesis methods such as sputtering, thermal oxidation, vacuum evaporation, and sol-gel have been reported in the literature [2]. Photoelectrochemical (PEC) cells with active semiconductor electrolyte junctions are considered to be efficient solar energy harvesters. Intensive research is going on how to use such systems in photosplitting of water for producing hydrogen (a much cleaner substitute for fossil fuels). An ideal semiconductor for this application should have a band gap in the range of $1.7 \mathrm{eV}$ to $2.1 \mathrm{eV}$ (a few tenth of eV larger than theoretical minimum value of $1.23 \mathrm{eV}$ needed for splitting water. Copper forms two different oxides: $\mathrm{Cu}_{2} \mathrm{O}$ which has direct band gap of $2.1 \mathrm{eV}$ and is 
therefore strongly absorbing only at wavelengths below $600 \mathrm{~nm}$ and whereas $\mathrm{CuO}$ with a band gap of $1.21 \mathrm{eV}$ to $1.51 \mathrm{eV}$ is absorbing throughout the visible region [3]. Solar selective absorber is one of the key components of solar collectors. Its optical properties and quality influence both the heat losses and gain. Therefore, it is important to develop a solar selective absorber which is characterized by a high absorbance, (particularly in the UV-Vis and NIR regions) as well as a low hemispherical emissivity, in the infrared region. In general, there are several different principles to design a solar selective surface based on the optical absorption mechanisms, such as semiconductor metal tandems, multilayer absorbers, metal dielectric composite coatings, surface texturing [4]. An ideal selective absorber surface is required to have a high solar absorbance $(\alpha)$ in the wavelength range of $0.3 \mu \mathrm{m}$ to $2 \mu \mathrm{m}$ and a low thermal emittance $(\epsilon)$ in the wavelength range of $2.5 \mu \mathrm{m}$ to $25 \mu \mathrm{m}$ at the operating temperature. Generally, black chrome, black nickel, black cobalt, black brass and copper oxide are commercially used as selective solar absorbers [5]. Black copper oxide $(\mathrm{CuO})$ appears to be a good candidate for solar selective coatings because it is inexpensive. Furthermore, it has demonstrated to have the desirable optical properties for solar photothermal conversion [6]. Cuprous oxide $\left(\mathrm{Cu}_{2} \mathrm{O}\right)$ and cupric oxide $(\mathrm{CuO})$, p-type semiconductors with narrow band gap energies of $2.2 \mathrm{eV}$ and $1.2 \mathrm{eV}$, respectively, have received much attention in recent years due to their widespread applications. Though $\mathrm{Cu}_{2} \mathrm{O}$ is not suitable for solar thermal systems owing to its high radiative recombination capability, it is widely applied in solar cells. $\mathrm{CuO}$ has been actively investigated as a selective absorber layer because of its high solar absorbance and low thermal emittance [5].

\section{Experimental}

\subsection{Thin film preparation by spray pyrolysis technique}

Our optimized values were as follows: the nozzle-substrate distance $(\mathrm{H}=30 \mathrm{~cm})$ and the carrier gas flow rate (air, $p=22 \mathrm{~L} / \mathrm{min}$ ). These conditions as well as nozzle aperture diameter and spraying duration were fixed and substrate temperature was varied between $350{ }^{\circ} \mathrm{C}$, $400{ }^{\circ} \mathrm{C}$, and $450{ }^{\circ} \mathrm{C}$, while the molarity was fixed at $0.2 \mathrm{M}$. Aqueous alcoholic solutions of $\mathrm{Cu}\left(\mathrm{CH}_{3} \mathrm{COO}\right)_{2} \cdot \mathrm{H}_{2} \mathrm{O}$ (Merck) with a volume of $20 \mathrm{~mL}$ were used as precursors for the copper films preparation. Deionized water (W) and absolute ethanol $\left(\mathrm{C}_{2} \mathrm{H}_{5} \mathrm{OH}, 99.9 \%\right.$, Merck $)$ were used as solvents (with an equal volume percent). The precursor solutions with molarity of $0.2 \mathrm{M}$, were sprayed perpendicularly onto preheated stainless steel substrates (previously cleaned with $\mathrm{HCl}$ acid and acetone, then mechanically polished and washed with distillated water) at various substrate temperatures. The as-deposited $\mathrm{CuO}$ thin films were annealed, at a temperature of $450{ }^{\circ} \mathrm{C}$ under nitrogen flow for $60 \mathrm{~min}$. Then, soda-lime glass were used as substrates (previously cleaned with $\mathrm{HCl}$ acid and acetone) in the same conditions as above. The substrate temperature was varied between $450{ }^{\circ} \mathrm{C}, 500{ }^{\circ} \mathrm{C}$ and $550{ }^{\circ} \mathrm{C}$ and thin films were prepared.

\subsection{Characterization techniques}

For samples prepared on soda-lime substrate, detection and confirmation of chemical bonds was performed by Fourier transmission infrared spectroscopy (FT-IR), obtained on the ALPHA spectrophotometer. Reflectance and transmittance spectra were measured on UV-Vis 100 scan spectrophotometer. X-ray diffraction (XRD) patterns of the samples were recorded on a Philips PW1800 $\mathrm{X}$-ray diffractometer with $\mathrm{CuK} \alpha$ radiation in $2 \theta$ range of $20^{\circ}$ to $70^{\circ}$. For samples prepared on steel substrate, UV-Vis-NIR spectrum was obtained on the AvaSpec-ULS2048LTEC spectrophotometer with an integrating sphere in a spectral interval of $0.3 \mu \mathrm{m}$ to $0.9 \mu \mathrm{m}$, while the infrared reflection spectra were obtained on the Perkin Elmer spectrophotometer in the range of $2.5 \mu \mathrm{m}$ to $20 \mu \mathrm{m}$. Reflectance for an interval of $0.9 \mu \mathrm{m}$ to $2.5 \mu \mathrm{m}$ was interpolated. The solar absorbance and thermal emissivity can be calculated through reflection measurement $R(\lambda)$ as follows [4]: 


$$
\begin{gathered}
\alpha=\frac{\int_{0.3}^{2.5}[1-R(\lambda)] P_{\text {sun }}(\lambda) d \lambda}{\int_{0.3}^{2.5} P_{\text {sun }}(\lambda) d \lambda} \\
\varepsilon=\frac{\int_{2.5}^{25}[1-R(\lambda)] P_{\mathrm{B}}(\lambda) d \lambda}{\int_{2.5}^{25} P_{\mathrm{B}}(\lambda) d \lambda}
\end{gathered}
$$

where $\mathrm{P}_{\text {sun }}(\lambda)$ is the normal solar spectral irradiance defined by the ISO standard 9845-1 (1992) [7], (we have used similar standard as ISO standard: IEC-904-3 [8]) for air mass AM 1.5 and $\mathrm{P}_{\mathrm{B}}(\lambda)$ is the spectral radiance of a black body at a temperature T. $P_{B}(\lambda)$ is, therefore, given by Plank law (equation 3). Equation 2 describes a portion of the black body radiation absorbed by a sample in relation to the total black-body radiation:

$$
\begin{gathered}
P_{\mathrm{B}}=\frac{C_{1}}{\lambda^{5}\left(e^{\frac{C_{2}}{\lambda T}}-1\right)} \\
C_{1}=3.743 \times 10^{-16} \mathrm{~W} \cdot \mathrm{m} \\
C_{2}=1.4387 \times 10^{-2} \mathrm{~m} \cdot \mathrm{K}
\end{gathered}
$$

\section{Results and discussion}

\subsection{Optical properties}

Reflection spectra of $\mathrm{CuO}$ thin films are shown in Fig. 1, which indicates that the samples have good selectivity, that is, the $\mathrm{CuO}$ thin films show high absorbance in the visible region and high reflectance in the IR region. From the reflectance spectra, the absorptivity and emissivity of the thin films were calculated and are given in Table 1, The absorbance values of $\mathrm{CuO}$ thin films shown in the table are: $0.86,0.85$ and 0.92 , which compared to the values of absorbance achieved by Kumar et al. $(0.90,0.89,0.88$ and 0.84$)$ [5] is a quite good result. Also the absorbance values are in good agreement with the results reported by Cindrella et al. [9] and Kumar et al. [10]. From the table, it is clear that the absorbance of thin film prepared at a temperature of $450{ }^{\circ} \mathrm{C}$ is higher than that of the films prepared at temperatures of $350{ }^{\circ} \mathrm{C}$ and $400{ }^{\circ} \mathrm{C}$. In other words, as the temperature of deposition increases, the absorbance of the sample at short wavelength (UV-Vis region) increases. However, comparing the absorbance and emittance, it is clear that the film prepared at $400{ }^{\circ} \mathrm{C}$ has the best selectivity.

High IR reflectance profile of these thin films may also be due to the scattering effect of light through the optically anisotropic monoclinic structure [5]. The sample prepared at $400{ }^{\circ} \mathrm{C}$ has the lowest thickness compared to those prepared at $350{ }^{\circ} \mathrm{C}$ and $450{ }^{\circ} \mathrm{C}$, and as a result, it has the lowest emissivity. The samples prepared on sodalime glass have $\mathrm{CuO}$ nanostructure which absorbs throughout the visible region. As a result, transmittance and reflectance spectra should have minimum value, which is presented in Fig. 2 and Fig. 3.

Table 1. Optical properties of thin films prepared at different substrate temperatures.

\begin{tabular}{cccc}
\hline Temperature $\left[{ }^{\circ} \mathrm{C}\right]$ & {$[\alpha]$} & {$[\epsilon]$} & {$[\mathrm{s}]$} \\
\hline \hline 350 & 0.86 & 0.45 & 1.91 \\
400 & 0.85 & 0.31 & 2.74 \\
450 & 0.92 & 0.55 & 1.67 \\
\hline
\end{tabular}

In order to calculate optical band gap, we can use the following equations where $\alpha$ is the absorption coefficient, $\mathrm{d}$ is the film thickness, $\mathrm{T}$ and $\mathrm{R}$ are transmittance and reflectance spectra of the film:

$$
\alpha=\frac{1}{d} \ln \left(\frac{\left(1-R^{2}\right)}{2 T}+\sqrt{\frac{\left(1-R^{4}\right)}{4 T^{2}}}+R^{2}\right)
$$

The optical band gap values of the thin films were determined from the intercept of $(\alpha \mathrm{h} v)^{2}$ vs. hv curves that are shown in Fig. 4 for different substrate temperatures:

$$
(\alpha h v)^{2}=B\left(h v-E_{g}\right)
$$

In equation $5, v$ is a photon energy, $\mathrm{E}_{g}$ is an optical band gap and B is a constant [11].

As shown in Fig. 4, the calculated band gap values are about 1.7 that is in a good agreement with some other works $[12,14]$.

\subsection{Structural properties}

X-ray diffraction (XRD) pattern of the sample prepared at $400{ }^{\circ} \mathrm{C}$ substrate temperature shown 

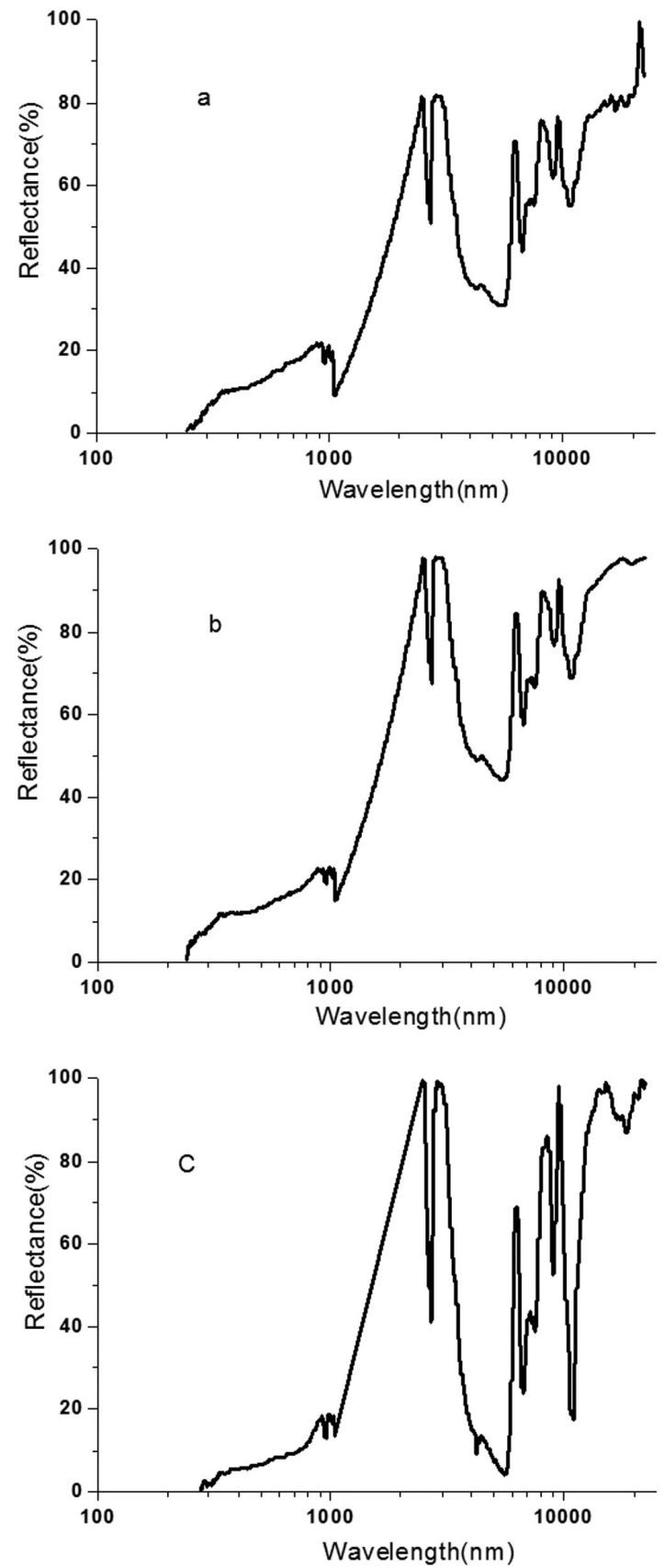

Fig. 1. Diffuse reflectance and FT-IR spectra for samples prepared at different substrate temperatures (a) $350{ }^{\circ} \mathrm{C}$, (b) $400{ }^{\circ} \mathrm{C}$, (c) $450{ }^{\circ} \mathrm{C}$.

in Fig. 5a, corresponds to JCPDS Card No. 05-0661, which is related to $\mathrm{CuO}$ and monoclinic crystalline system. Similar result has been obtained by Oral et al. [14]. Peaks that are marked with $\mathrm{SS}$, are related to

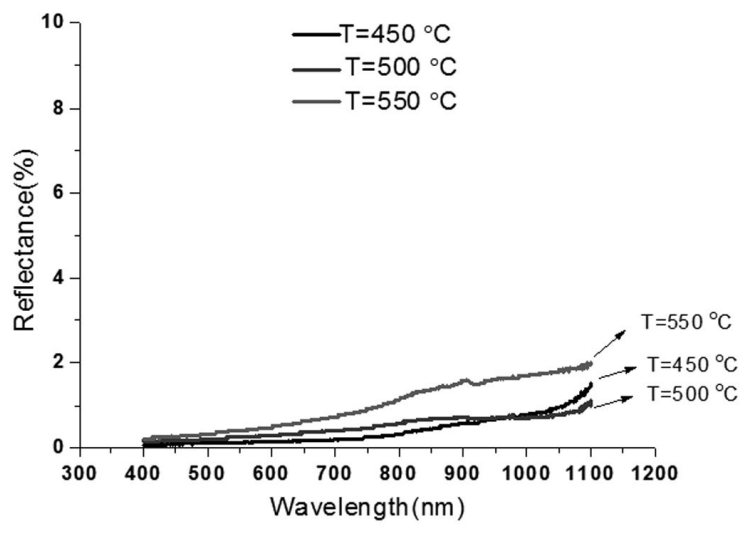

Fig. 2. Reflectance spectra for samples prepared at different substrate temperatures.

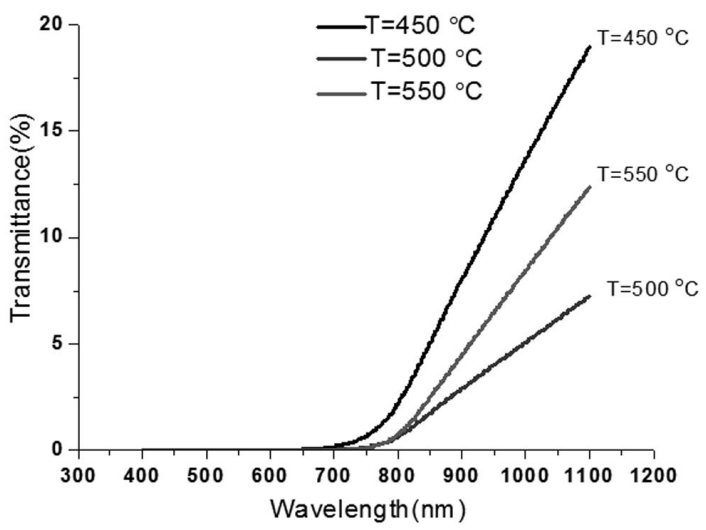

Fig. 3. Transmittance spectra for samples prepared at different substrate temperatures.

stainless steel. Crystallite sizes related to $\left(\begin{array}{lll}-1 & 1 & 1\end{array}\right)$ and $\left(\begin{array}{lll}1 & 1 & 1\end{array}\right)$ orientations have been calculated from Scherer equation, and the values of $35 \mathrm{~nm}$ and $42 \mathrm{~nm}$, respectively have been obtained:

$$
d=\frac{k \lambda}{\beta \cos \theta}
$$

where $\lambda$ is the wavelength and $\mathrm{k}$ is the correction factor that is equal to $0.89, \beta$ is the FWHM (Full Width at Half Maximum) and $\theta$ is the Bragg diffraction angle [13]. X-ray diffraction (XRD) patterns of the samples prepared on soda-lime glass substrate, at different substrate temperatures, are shown in Fig. 5b. The patterns correspond to JCPDS Card No. 05-0661, which is related to 

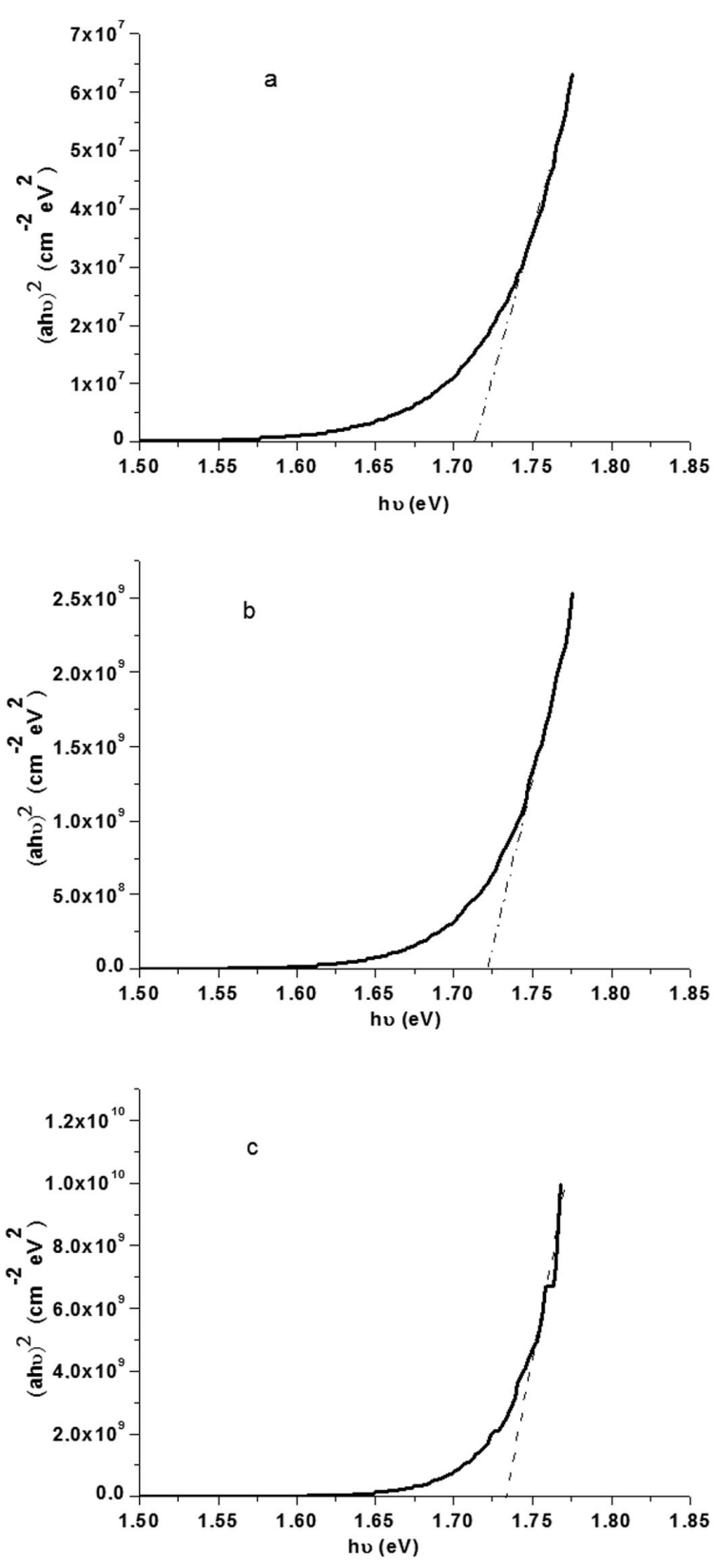

Fig. 4. The plots of $(\alpha \mathrm{h} v)^{2}$ spectra vs. $\mathrm{h} v$ for samples prepared at different substrate temperatures (a) $450{ }^{\circ} \mathrm{C}$, (b) $500{ }^{\circ} \mathrm{C}$, (c) $550{ }^{\circ} \mathrm{C}$.

$\mathrm{CuO}$ and monoclinic crystalline system, similar to Oral et al. results [14]. Our results are also in a good agreement with Cindrella et al. [9] and $\mathrm{Ku}-$ mar et al. [10] results. Variation of crystallite size corresponding to the peaks located at the angles of $35.22^{\circ}$ and $38.56^{\circ}$ with variation of substrate temperature, are shown in Table 2. With increasing substrate temperature from $450{ }^{\circ} \mathrm{C}$ to $500{ }^{\circ} \mathrm{C}$, crystallite size decreases and then, with increasing temperature to $550{ }^{\circ} \mathrm{C}$, crystallite size increases which is in agreement with Chauhan et al. results [15].
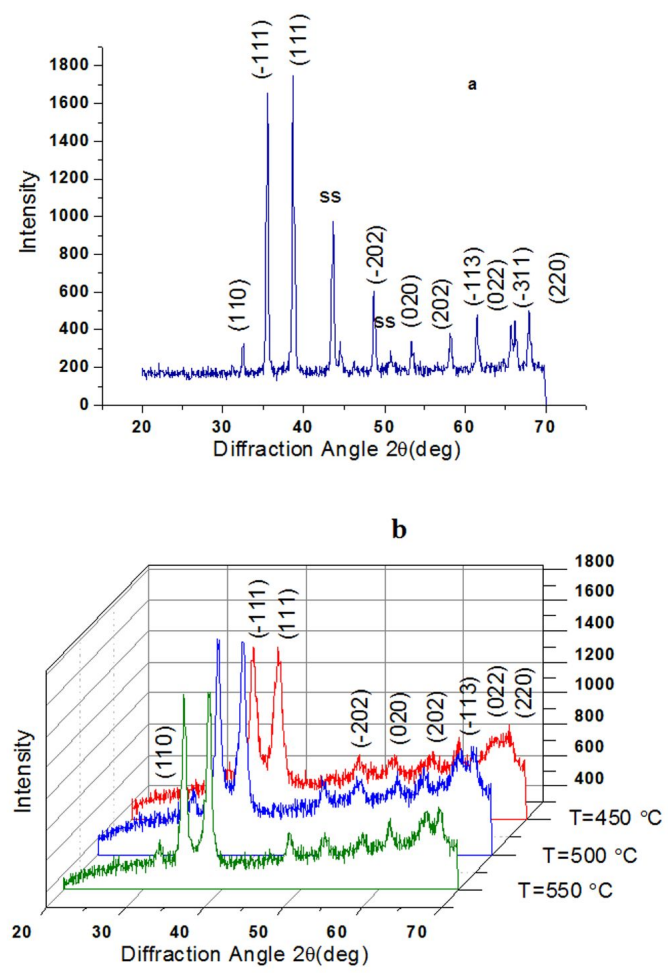

Fig. 5. X-ray diffraction (XRD) patterns for samples prepared (a) on stainless steel substrates at $400{ }^{\circ} \mathrm{C}$ substrate temperature (b) on soda-lime glass substrate at different substrate temperatures.

Table 2. Crystallite size for samples prepared at different substrate temperatures.

\begin{tabular}{|c|c|c|c|c|}
\hline \multicolumn{2}{|c|}{ Crystallite size $[\mathrm{nm}]$} & \multicolumn{2}{|c|}{ FWHM } & \multirow{2}{*}{$\begin{array}{c}\text { Substrate } \\
\text { temperature }\left[{ }^{\circ} \mathrm{C}\right]\end{array}$} \\
\hline$\left(\begin{array}{lll}1 & 1 & 1\end{array}\right)$ & $\left(\begin{array}{lll}-1 & 1 & 1\end{array}\right)$ & $\left(\begin{array}{lll}1 & 1 & 1\end{array}\right)$ & $\left(\begin{array}{lll}-1 & 1 & 1\end{array}\right)$ & \\
\hline 36 & 43 & 0.2362 & 0.1968 & 450 \\
\hline 21 & 26 & 0.3936 & 0.3149 & 500 \\
\hline 27 & 34 & 0.3149 & 0.24 & 550 \\
\hline
\end{tabular}

\subsection{FT-IR spectroscopy}

FT-IR spectroscopy results of thin films prepared on soda-lime glass at different substrate 


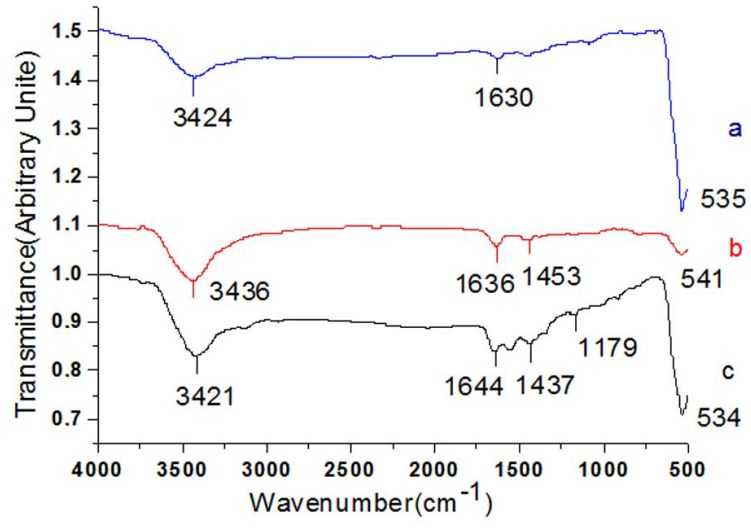

Fig. 6. FT-IR spectroscopy results for samples prepared at different substrate temperatures (a) $450{ }^{\circ} \mathrm{C}$, (b) $500{ }^{\circ} \mathrm{C}$, (c) $550{ }^{\circ} \mathrm{C}$.

temperatures are shown in Fig. 6. Existence of absorption bands at $534 \mathrm{~cm}^{-1}, 541 \mathrm{~cm}^{-1}$ and $535 \mathrm{~cm}^{-1}$ can be assigned to the stretching vibration of $\mathrm{Cu}-\mathrm{O}$, that is in agreement with former studies [1, 16]. The peaks in the range of $1000 \mathrm{~cm}^{-1}$ to $1400 \mathrm{~cm}^{-1}$ and $1630 \mathrm{~cm}^{-1}$ to $1650 \mathrm{~cm}^{-1}$, can be assigned to the bending modes vibration of $\mathrm{O}-\mathrm{H}$ and $\mathrm{H}-\mathrm{O}-\mathrm{H}$, respectively [17, 18]. The peaks in the range of $3400 \mathrm{~cm}^{-1}$ to $3850 \mathrm{~cm}^{-1}$ are related to stretching vibrations of $\mathrm{OH}$ [19]. As it is shown in the figure, increasing substrate temperature caused a decrease in absorption band related to $\mathrm{OH}$ vibrations. It is known that frequency is inversely proportional to bond length [20]. For adjusting the results from FT-IR spectroscopy and X-ray diffraction (XRD) patterns, absorption bands related to different substrate temperatures have been investigated. As it is shown in Fig. 6, absorption frequency increases with increasing temperature from $450{ }^{\circ} \mathrm{C}$ to $500{ }^{\circ} \mathrm{C}$, and then decreases at $550{ }^{\circ} \mathrm{C}$, which can be attributed to bond length related to crystallite size. This means that the bond length decreases by increasing absorption frequency from $534 \mathrm{~cm}^{-1}$ to $541 \mathrm{~cm}^{-1}$, and as a result, crystallite size decreases. Also, the bond length increases by decreasing absorption frequency from $541 \mathrm{~cm}^{-1}$ to $535 \mathrm{~cm}^{-1}$, and, as a result, crystallite size increases, which is in a good agreement with X-ray diffraction (XRD) results.

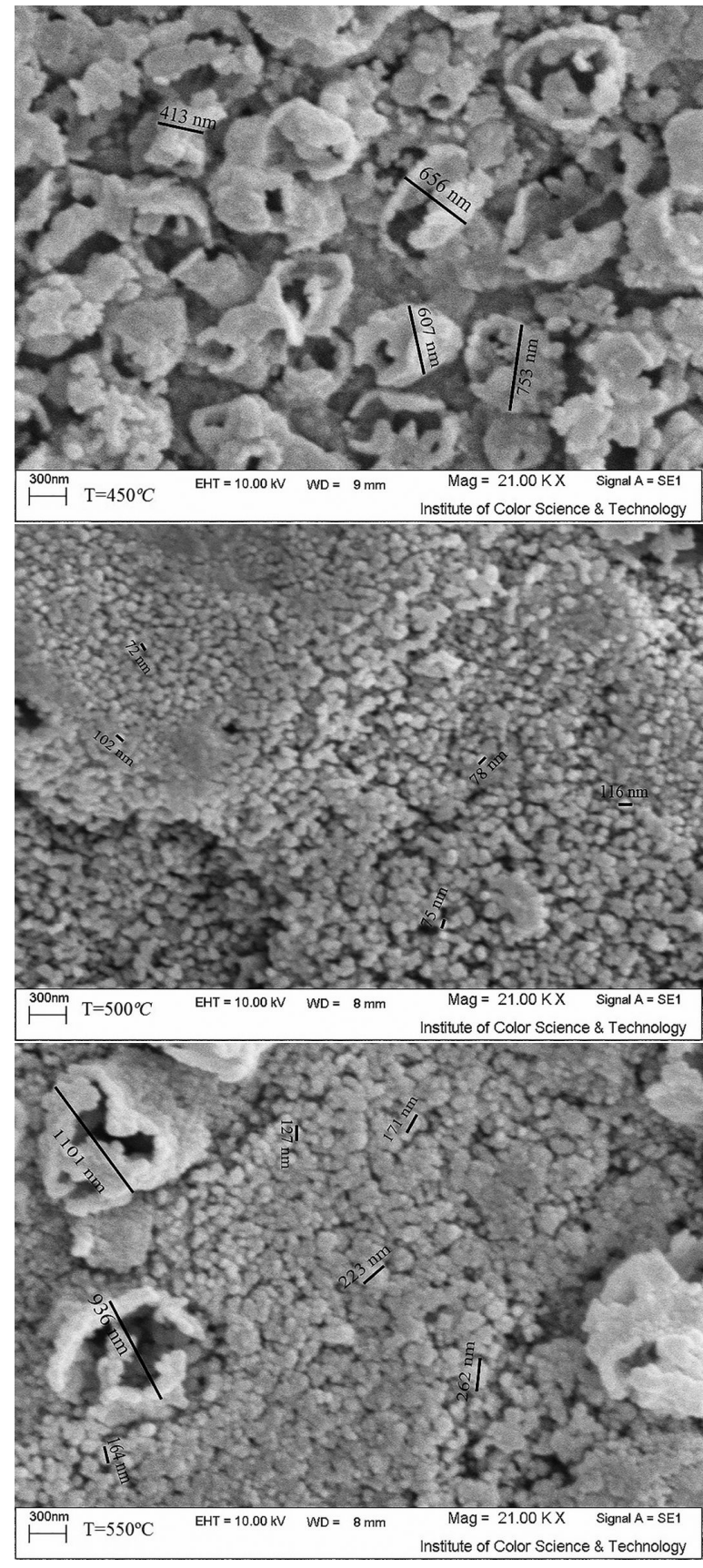

Fig. 7. SEM images of samples prepared at different substrate temperatures.

\subsection{Morphology studies}

The morphological features of $\mathrm{CuO}$ thin films were analyzed using Scanning Electron Microscope (SEM) and the resultant images are shown in Fig. 7. The figure shows SEM images of $\mathrm{CuO}$ 
thin film prepared at different substrate temperatures. Grain size decreases by increasing substrate temperature from $450{ }^{\circ} \mathrm{C}$ to $500{ }^{\circ} \mathrm{C}$, and then it increases by increasing substrate temperature from $500{ }^{\circ} \mathrm{C}$ to $550{ }^{\circ} \mathrm{C}$. According to the SEM images, the grain sizes are $413 \mathrm{~nm}, 72 \mathrm{~nm}$ and $127 \mathrm{~nm}$ at substrate temperatures of $450{ }^{\circ} \mathrm{C}, 500{ }^{\circ} \mathrm{C}$ and $550{ }^{\circ} \mathrm{C}$, respectively, what means that the variations of grain sizes obtained from SEM images are in a good agreement with FT-IR spectroscopy results and variations of crystallite size obtained from X-ray diffraction studies which are shown in Table 2 . At $500{ }^{\circ} \mathrm{C}$ substrate temperature, the decrease in grain size can be caused by decreasing grain mobility, but the grain mobility increases and leads to an increase in grain size by increasing substrate temperature to $550{ }^{\circ} \mathrm{C}$. High absorbance of these layers is due to nanometer scale pores which absorb light like a light trap in the visible region.

\section{Conclusions}

Single-phase $\mathrm{CuO}$ thin films with monoclinic structure were produced from precursor solutions prepared by dissolving copper acetate in water and ethanol followed by spray pyrolysis on glass and stainless steel substrates. Optical band gap of the thin films, measured by using an UV-Vis scanning spectrophotometer was about $1.7 \mathrm{eV}$. As a result, the thin films showed absorption in the visible region. For thin films prepared on stainless steel substrates, selectivity of the films was affected by variation of substrate temperature. The best selectivity was achieved for the sample prepared at $400{ }^{\circ} \mathrm{C}$ substrate temperature.

\section{Acknowledgements}

The authors gratefully acknowledge the Research Department of University of Guilan.

\section{References}

[1] Papadimitropoulos G., Vourdas N., VAMVAKas V., Davazoglou D., J. Phys. Conf., 10 (2005), 182.
[2] Arunkumar D., Francis P., Merlineshyla J., Arch. Appl. Sci. Res., 4 (2012), 2174.

[3] Yatendra S., Anshul A., Rohit S., Vibha R., S AHAB D., Int. J. Hydrogen. Energ., 29 (2004), 131.

[4] Xiudi X., Lei M., Gang X., Limei L., Zhanmin S., Ning W., Sakae T., Appl. Surf. Sci., 257 (2011), 10729.

[5] Kumar S.K., Murugesan S., Suresh S., Mater. Chem. Phys., 143 (2014), 709.

[6] Barreracalva E., Mendezvivar J., Ortegalopez M., HuertaArcos L., Morales Corona J., Olayogonzalez R., Adv. Mater. Sci. Eng., (2008).

[7] http://www.iso.org/iso_catalogue/ catalogue_tc.

[8] Myers D.R., EMery K., Technical report, National Renewable Energy Laboratory, 2002.

[9] Cindrella L., Prabhu S., Appl. Surf. Sci., 378 (2016), 245.

[10] Kumar S.K., Suresh S., Murugesan S., Paulrau S., J. Sol. Energ.-T. ASME, 94 (2013), 299.

[11] Caglar M., Yakuphanoglu F., Appl. Surf. Sci., 258 (2012), 3039.

[12] Lamrizeggar M., Chabane L., Aida M.S., Attaf N., Zebbar N., Mat. Sci. Semicon. Proc., 30 (2015), 645.

[13] Yue G.H., Peng D.L., J. Alloy. Compd., 468 (2009), 254.

[14] Oral A.Y., Mensur E., Aslan M.H., Basaran E., Mater. Chem. Phys., 83 (2004), 140.

[15] Chauhan D., Satsangi V.R., Dass S., ShrivasTAV R., B. Mater. Sci., 29 (2006), 709.

[16] Rahimnejad S., Rahmansetayesh S., Gholami M.R., J. Iran. Chem. Soc., 5 (2008), 367.

[17] Mozaffari M., Manouchehri S., Yousefi M.H., Amighian J., J. Magn. Magn. Mater., 322 (2010), 383.

[18] Goodarznaseri M., Saion E.B., AbbastabaraHANGAR H., HAShim M., ShaARI A.H., J. Magn. Magn. Mater, 323 (2011), 1745.

[19] Jafari A., Boustani K., FarJamishayesteh S., J. Supercond. Nov. Magn., 27 (2014), 187.

[20] Salah L.M., Moustafa A.M., Ahmedfarag I.S., Ceram. Int., 38 (2012), 5605. 